\title{
Evolution of the Global Climate Governance System and Its Implications
}

Yu Hongyuan

\begin{abstract}
Climate change has emerged as one of the top security challenges in the early 21st century. It is now widely acknowledged that international cooperation and collective action will be the key to addressing challenges caused by climate change. This article will give an explanation on the evolution of the global climate change governance system by linking history, governance, and diplomacy. The challenge of climate change involves not only international competition for new energy but also related adjustments in the global governance pattern. Specifically, the carbon emission reduction to be discussed at the 2015 UN Paris Climate Conference will still be problematic, and negotiations with regard to financing mechanisms between developed and developing countries will remain in doubt. Furthermore, the attitudes of the two sides toward common but differentiated responsibilities (CBDR) and the intended nationally determined contributions (INDCs) are disparate. In addition, negotiations among China, the UN, the U.S., and the EU are decisive in
\end{abstract}

Yu Hongyuan is Professor and Director of the Institute for Comparative Politics and Public Policy at the Shanghai Institutes for International Studies. He can be reached at yuhongyuan@siis.org.cn, Shanghai Institutes for International Studies, 195-15 Tianlin Road, Shanghai 200233, China.

(C) 2015 World Century Publishing Corporation and Shanghai Institutes for International Studies China Quarterly of International Strategic Studies, Vol. 1, No. 3, 423-446

DOI: 10.1142/S2377740015500220 
tackling this tricky matter. Finally, this article outlines some potential diplomatic options for China's future developmental trend.

Keywords: International system; climate diplomacy; governance structure.

Climate change, the major and potentially most devastating challenge confronting the world today, not only leads to environmental degradation/ scarcity and a radical reform of the energy mix among industrial countries, but brings about changes to the international system as well. It is undeniable that climate change has attracted worldwide attention, and it has been widely acknowledged that international cooperation or collective action will be the key to addressing the challenges caused by climate change. As UN Secretary-General Ban Ki-Moon put it, "climate change is altering the geopolitical landscape," as manifested in ever more intense competition over Arctic resources, increased intra-state and inter-state migration and rising sea levels. ${ }^{1}$ It is now clear that all countries in the world should work together to combat the climate disaster. According to the United Nations Framework Convention on Climate Change (UNFCCC), "If the international community doesn't get stronger actions, we will get very dangerous climate change." ${ }^{2}$ In the 1990s, the UNFCCC and the Kyoto Protocol replaced the ideological confrontation of the Cold War with antagonism between developing and developed countries, which turned climate change from a purely scientific topic to one that must mingle with political and development issues. Under such circumstances, climate change negotiations have been prioritized on the global governance agenda, but the actual

${ }^{1}$ UN News Center, "Speech by United Nations Secretary-General Ban Ki-Moon to World Climate Conference-3," UN News Service, September 3, 2009, http://www.un.org/ apps/news/infocus/sgspeeches/search_full.asp?statID $=568$.

${ }^{2}$ Alex Nussbaum, "Rich-Poor Divide Threatens Climate Goal: UN Talks in Peru Failed to Lock Developing Nations into Binding Rules on Fossil Fuel," Bloomberg News, December 15, 2014, http://www.google.com.hk/url?q=http://www.bloomberg.com/politics/articles/ 2014-12-14/richpoor-climate-divide-threatens-prospects-for-new-deal\&sa=U\&ei=L-tVVdrwKMrlsATKn4HoDA\&ved=0CBMQFjAA\&usg=AFQjCNH-EJnsyDQ0ND2y7vDS0e1bCiUOuw. 
negotiations themselves have become increasingly more difficult. ${ }^{3}$ On the other hand, international collective action to manage the crisis has been far from effective. International cooperation on climate change is a social, political, and economic problem. It involves various sectors of the national and social economy, thus has an important bearing on political legitimacy and stability of all nations. Obviously, it will take time for the international community to reach a consensus on actions to manage global climate change; we are always confronted with two questions: why is it so difficult to manage the global climate governance ${ }^{4}$ What factors hamper the effectiveness and fairness of international cooperation? This article attempts to give an explanation on some of these challenges and the evolution of climate change governance by linking history, governance, and diplomacy.

\section{A Short History of Global Climate Governance}

From the 1992 Rio Summit, through the Kyoto Conference, the Bali Roadmap, and the Durban Platform ${ }^{5}$ to the forthcoming 2015 Paris United Nations Climate Conference, a generation has passed since world leaders began to seriously consider the problems and impacts of climate change. Since the early 1990s when UNFCCC officially entered into force, international climate negotiations have ensued for more than 20 years. The last two decades showcased the tremendous difficulty of bringing together countries with different national interests to accomplish global governance in any specific area. However, the process has also revealed the potential for global climate governance to become the next major focal area for international cooperation. Recent progress made at Lima has reflected the will of the international community to fight against the emerging threat.

Beginning with the United Nations Conference on Human Environment in 1972, political leaders brought these issues of climate change to the agenda of international politics. In the 1990s, environmental issues became

3Jairam Ramesh, “The Rocky Road to Paris,” India Times, December 15, 2014.

${ }^{4}$ Kofi Annan, "Climate Crisis: Who will Act?" New York Times, November 25, 2013, http://www.nytimes.com/2013/11/25/opinion/climate-crisis-who-will-act.html.

${ }^{5}$ Ben Webster, "Lima Climate Change Deal Doesn't Force Countries to Set Targets," The Times, December 15, 2014, http://www.thetimes.co.uk/tto/environment/article4297120.ece. 
headlines in the global media. ${ }^{6}$ The development of climate change negotiations in the early 1990s rode a wave of environmental activism, and the Intergovernmental Negotiating Committee for a Framework Convention on Climate Change (INC/FCCC) held five sessions between February 1991 and May 1992. During these gatherings, participants from over 150 countries discussed the difficult and contentious issues regarding binding commitments, targets and timetables for the reduction of carbon dioxide emissions, financial mechanisms, technology transfer, and the "common but differentiated responsibilities (CBDR)" of developed and developing countries. ${ }^{7}$ The UNFCCC was adopted on May 9, 1992, in Rio de Janeiro, Brazil, and opened for signature at the UN Conference on Environment and Development in June 1992 in Rio, where it received 155 signatures. The UNFCCC with universal membership entered into force on March 21, 1994, after receiving the requisite 50 ratifications.

The Kyoto Protocol has always been regarded as the turning point for climate governance and as the legally binding mitigation for all developed nations. ${ }^{8}$ By 1997, more than 150 nations had adopted the Kyoto Protocol. The protocol was created to bring the amount of global greenhouse gases to 7 percent below the 1990 level. The gas emissions Though the CBDR principle was established over two decades ago, international cooperation on climate change has faced several challenges due to self-interested concerns of individual countries. were to be reduced between the years of 2008 and 2012. The U.S. agreed to assume the reduction of seven percent, Japan was to assume six percent, and the EU members to jointly assume eight percent. In 2007, the Bali Roadmap was

${ }^{6}$ Lynton Caldwell, International Environmental Policy Emergence and Dimensions (Durham: Duke University Press, 1990).

7James K. Sebenius, “Towards a Winning Climate Coalition," in Irving M. Mintzer and J. A. Leonard, eds., Negotiating Climate Change: The Inside Story of the Rio Convention (Cambridge: Cambridge University Press, 1995), pp. 277-320.

${ }^{8}$ Thomas Homer-Dixon, Environment, Scarcity, and Violence (Princeton N.J.: Princeton University Press, 1999), p. 48. 
accepted to show that the developing world would be likely to accept mandatory caps (carbon emission reduction timetable and goal) with measurable, veritable, and reportable assistance from the developed world, together with the voluntary approaches of tackling climate change.

In 2009, solutions with all-round knowledge-based efforts were discussed, negotiated for and finalized in the Copenhagen Accord as the desired future scenario for the world. In 2011, three important achievements were accomplished in Durban: Kyoto extension, Durban Platform for Enhanced Action to discuss the post-2020 global emissions scheme, and the green climate fund. The Durban conference played a vital role as it supports the Kyoto Protocol, which is the only legally binding arrangement that can be applied to industrial countries including the EU and obtains a few others' commitments to a second round of pledges from 2012 to 2017. It will also require all the countries in the world to work toward the first post2020 global climate roadmap with legal force by 2015, particularly, the EU and 10 other countries agreeing to a second phase of Kyoto. China, the United States, and other countries agree to finalize a legally binding agreement by 2015 that will lay down concrete goals for reductions starting from 2020. In the 2013 Warsaw Climate Conference, the international community agreed to invite all parties to prepare for their Intended Nationally Determined Contributions (INDCs), ${ }^{9}$ and requested all to provide information on their individual INDCs for clarity on the level of ambition. In 2014, under the Lima Accord, all countries were required to submit their INDCs plans that would be posted on a UN website and made available to the public. According to the UNFCCC, these INDCs will form the foundation for climate action after 2020 when the new agreement is set to come into effect. As Madame Christiana Figueres, Executive Secretary of the UNFCCC, put it,

Governments arrived in Lima on a wave of positive news and optimism resulting from the climate action announcements of the European Union, China and the United States to the scaling up of pledges for the Green Climate Fund. ${ }^{10}$

${ }^{9}$ Frank McDonald, “Climate Deal Reached in Warsaw but Critics Say it is too Weak in Face of Crisis," Irish Times, November 25, 2013.

${ }^{10}$ UN News Center, “COP20: Ban Ki-Moon Hails Delegates for Paving Way to 'Meaningful' Climate Agreement," December 14, 2014, http://www.un.org/apps/news/story. asp?NewsID=49600\#.Vforw5UVhjo. 
However,

the burden of tackling climate change will decisively shift to developing countries, making their efforts toward poverty reduction and sustainable development difficult and expensive. ${ }^{11}$

Recently there has been much positive progress in the negotiations working toward the Paris climate conference. The UNFCCC Secretariat organized three rounds of negotiation conferences. The Durban Platform for Enhanced Action (ADB) finally entered the consultation phase of "contact group," thus gaining access to the substantive content; in September 2014, the UN Climate Summit in New York succeeded in improving political consensus among UN member states, attracting financial support, and responding to climate change comprehensively; in October 2014, the Europe Council passed the 2030 Framework for Climate and Energy Policies, becoming the first among the major economies to formally announce its climate change policies and the quantified emission reduction target of greenhouse gases; in November 2014, the U.S.-China Joint Announcement on Climate Change was signed to articulate their ambitions to cope with climate change after 2020 respectively; afterwards, the U.S. and India also reached a consensus on fluorinated gases reduction. These positive actions of major economies have become the driving force for climate negotiations. In December 2014, as earlier mentioned, the Lima conference passed the Lima Accord, under which all countries must submit plans that would be made publicly available. The four-page Lima Accord can be regarded as the most important achievement of the 2014 climate negotiations. ${ }^{12}$ The document reaffirms the principles of the 2015 Paris negotiation, the definite timetable to submit INDCs and corresponding information, as well as the arrangement to improve the levels of emission reduction before 2020 . Considering that the Lima Accord requires all the outcomes of previous

11 "Lima Summit Shows Climate Politics Lagging behind Real World Momentum," Climate Action Network, December 14, 2014, http://www.climatenetwork.org/press-release/ lima-summit-shows-climate-politics-lagging-behind-real-world-momentum.

12 "Setting the Stage for Paris," Hindustan Times, December 16, 2014, http://www. highbeam.com/doc/1P3-3527051101.html. 
Table 1. The Development of Climate Negotiation.

1992 Rio Earth Summit

Rio signatories over 150 countries to the UNFCCC committed to achieving "stabilization of Greenhouse Gas (GHG) concentrations in the atmosphere at a level that would prevent dangerous interference with the climate system."

1994 Entry into force of the Climate Convention

1995 First Conference of the Parties (COP1), Berlin, Germany

Berlin Mandate, "Common but Differential Responsibilities" for developing country (Group 77 \& China)

1997 COP3, Kyoto

Over 160 countries sign the Kyoto Protocol. Industrialized signatories commit to binding GHG reductions of a global average of 5.2\% below 1990 levels for the period of 2008-2012.

1998 COP4, Buenos Aires, Argentina

Parties set deadline to decide on Kyoto rules. The implementation of reducing the GHG in developing countries.

1999 COP5, Bonn, Germany

Parties intensify work plan in order to meet COP4 deadlines "Bonn Agreement".

2000 COP6, The Hague, Netherlands

Opportunity to close Kyoto loopholes and ensure real GHG reductions.

2001 COP7, Marrakech

The 165 nations endorsing the Marrakech consensus adopt guidelines for implementing the Kyoto Protocol. Nations can thus proceed to introduce the necessary domestic legislation to ratify the Kyoto Protocol.

2002 COP8, New Delhi

China ratified the Kyoto protocol.

The Second World Summit on Sustainable Development in Johannesburg in September 2002.

2005 COP11and MOP1, Montreal, Canada

The Kyoto protocol came into effect. The Montreal Action Plan is an agreement to extend the life of the Kyoto Protocol beyond its 2012 expiration date and negotiate deeper cuts in greenhouse-gas emissions.

2007 COP-13 and MOP-3, Bali, Indonesia

The negotiation focused on the post-2012 framework on GHG reduction.

2009 COP-15 and MOP-5, Copenhagen

Prospective adoption of the post-2012 climate change regime.

2011 COP-17 and MOP-7, Durban

Durban Platform for Enhanced Action made all countries at the UN climate change conference confirm to a legal framework toward a new global pact that would bring all major emitters - developed and developing - into its fold.

2013 COP-19 and MOP-9, Warsaw

Warsaw Consensus reaffirmed the core principle that the deal will be "applicable to all" 195 parties to the UN climate convention, with no differentiation between rich and poor nations as under the Kyoto Protocol.

2014 COP-20 and MOP-20, Lima

The Lima Accord requires all countries to submit INDCs that would be posted on a United Nations website.

Source: www.unfccc.int (compiled by author). 
negotiations be put in a legally-binding framework, a tough goal to be reached in the 2015 Paris negotiation, it is necessary for each country to make preparations to defend their positions, as well as make necessary compromises.

Since most economies and large green-

Much progress has house gas emitters have expressed their ambitions for combating climate change, UN Secretary-General Ban Ki-Moon called for "all parties, especially the world's major economies, to submit ambitious national commitments well in advance of Paris." ${ }^{13}$ The United States has committed to a 26 to 28 percent reduction below the 2005 level in 2025, and will make it a legacy issue considering the oppobeen made in the past few years, especially in terms of the increasing determination of major carbon emitters. sition in Congress is still the main barrier. The EU was one of the first parties to announce its INDC, based on the target to reduce emissions by 40 percent by 2030. India is likely to support energy efficiency improvement measures that will not hold back the economy, whilst China has expressed its intent to peak carbon dioxide emissions around 2030 and to increase its share of non-fossil fuels in primary energy consumption to around 20 percent.

\section{Changes of the Climate Governance System}

The general trends can be observed from the recent developments of climate change negotiations. The INDCs, which will be finalized at Paris by the end of this year, have become the new foundation of the climate governance system and the CBDR principle would probably be further adapted with new interpretations. This trend reflects the situation that the two major blocs (developing countries vs. developed countries) are still in existence, but countries in the same bloc are acting in their own interests.

13 "Secretary-General Ban Ki-Moon's Remarks on the Momentum for Change," December 4, 2012, http://www.un.org/climatechange/blog/2012/12/secretary-general-ban-kimoons-remarks-on-the-momentum-for-change/. 
Table 2. Submission of INDCs from Different Countries.

\begin{tabular}{ll}
\hline Country & \multicolumn{1}{c}{ INDC Content } \\
\hline Mexico & $\begin{array}{l}\text { Unconditional: 25\% reduction below BAU for the year 2030; } \\
\text { Conditional: } 40 \% \text { reduction below BAU for the year 2030 }\end{array}$ \\
Russia & Limiting emission to 70-75\% of 1990 levels \\
U.S. & 26-28\% reduction from 2005 level in 2025 \\
Norway & At least 40\% domestic reduction compared to 1990 by 2030 \\
EU & At least 40\% domestic reduction compared to 1990 by 2030 \\
Switzerland & 50\% reduction relative to 1990 levels by 2030 \\
China & $\begin{array}{l}\text { To achieve peak carbon dioxide emissions by approximately 2030, or } \\
\text { sooner as best efforts allow; to lower carbon dioxide emissions per unit } \\
\text { of GDP by 60\% to 65\% from 2005 levels; to increase the share of }\end{array}$ \\
& non-fossil fuels in the primary energy mix to approximately 20\% \\
\hline
\end{tabular}

Source: www.unfccc.int (compiled by author).

Finally, the new emerging developing countries would be the focus of climate governance given their rapid economic growth.

\section{Change of the Principle: From CBDR to INDCs}

The growing reluctance of developed countries to pay necessary attention, along with developing countries' economic and technological backwardness in energy and low-carbon management, results in the norms and rules of climate governance being in constant flux. The INDCs are the new norm for developing countries to upgrade their environmental standards and responsibilities on emission targets. The INDCs have replaced the principle of CBDR as the foundation of the climate governance system, and will continue to be the top priority for global climate change governance. Previously, the CBDR-based climate governance system had achieved global consensus in the UNFCCC. This principle means that industrialized, wealthy countries bear most responsibilities for global warming because of their historical emissions of greenhouse gases for more than three hundred years. Furthermore, developed countries' emissions per capita remain far above those of developing countries, implying that their responsibilities continue to exist. The INDCs will now serve as a basis for achieving the goals of the UNFCCC based on a bottom-up approach and pursuit of a lowcarbon growth path. 
The INDCs are intended to build a reference on how much effort an individual country should make to reduce carbon emissions and narrow the gap between developed and developing countries, based on their national circumstances. For those concerned about climate change, responsibilities for reducing emissions by the required amount should be divided between developed and developing countries, an issue which will continue to be at the core of climate change concerns. In the 2015 climate negotiations, there will no longer be two categories of carbon emitters as in the Kyoto Protocol of 1997; INDCs will require every country to reveal its emission reduction responsibilities to the international community.

In addition, under the INDCs, every country will take mitigating actions and those that are willing to do so also should take adaptive actions. In 2015, the international community is working hard to ensure that the signatories submit the spectrum and information of INDCs, in order to make the INDCs fair and ambitious. A second goal is to finalize every element in the basic text of the 2015 Agreement, particularly on: adaptation capacity building, climate finance, technology transfer, and private sector participation. Thirdly, a concrete work plan should be established to strengthen the promise of emission reduction.

Moreover, the principle of CBDR continues to be revised and reinterpreted. The CBDR principle essentially requires developed countries to reduce their carbon dioxide emissions whilst developing countries and underdeveloped countries are given a choice whether to do so. Without the responsibilities of emission reduction, these developing countries have a broad basis for cooperation. Developing countries hope to continue with the principle of CBDR as in the UNFCCC and the Kyoto Protocol, and they always insist in retaining the convention framework and the basic principle of CDBR. Unsurprisingly, developed countries object to the "dichotomy" of the original signatories, advocating for the conventional principles to be reinterpreted given that economic progress has been achieved by some countries. The Like-Minded Developing Countries (LMDC) bloc has spoken firmly on maintaining the CBDR principle, suggesting that developed countries need to act first, because they are the culprit of climate change. The Group of 77 (G77), the EU, and some from the LMDC bloc came together in a coordinated strategic move. The Philippines' climate negotiator from 
the LMDC group was primarily responsible for pushing through the Lima outcome, ${ }^{14}$ which exists as a "red line" without mutual concession from the two groups. Ultimately, the Lima outcome reiterated in the foreword that the Durban Platform would be "under the convention," instructed by the principles of the convention and "the 2015 agreement" emphasized in the text should reflect the CBDR principle "in the light of different national circumstances." Thus the principle of "common but differentiated responsibilities" will be reinforced with some new interpretations in the 2015 negotiation, as the negotiation text insists:

\section{INDCs are replacing \\ CBDR as the \\ underlying principle of global climate governance, highlighting responsibilities of every nation, whether developing or developed.}

Underscore (their) commitment to reaching an ambitious agreement in 2015 that reflects the principle of common but differentiated responsibilities and respective capabilities, in the light of different national circumstances.

Thus, the existing CBDR principle in climate change will face further dilution.

The INDCs are replacing the principle of CBDR and respective capacities as the foundation of the climate governance system, and will continue to be the top priority for global climate change governance.

Historical responsibilities and distinctions between the South and the North were both important points during all climate negotiations. ${ }^{15}$ The

${ }^{14}$ Linh Do, “Doha, a Process Won that Won't Solve Climate Change," Thomson Reuters Foundation, December 8, 2012, http://www.trust.org/alertnet/news/change-final-doha-update; Timmons Roberts and Guy Edwards, "A New Latin American Climate Negotiating Group: The Greenest Shoots in the Doha Desert," The Brookings Institution, December 15, 2012, http://www.brookings.edu/blogs/up-front/posts/2012/12/12-latin-america-climateroberts.

${ }^{15}$ Agence France-Presse, "UN Talks Approve Climate Pact Principles," Globalpost, November 24, 2013, http://www.globalpost.com/dispatch/news/afp/131123/un-talks-approve-climate-pact-principles-1. 
U.S. climate negotiator argued that "the 'firewall' between developed and developing countries enshrined in previous agreements must be removed." ${ }^{16}$ Developed countries had requested and would continue to request the $\mathrm{UN}$ to revise or redefine the principle of CBDR and make

efforts to breach the firewall between developed and developing countries enshrined in the Kyoto Protocol by referring to major economies as distinct from other developing countries. ${ }^{17}$

The 2014 U.S.-China Joint Announcement on Climate Change was a vital impetus for the new interpretation of CBDR. It reflects the good image of China as it not only means China has accepted its responsibility, but also safeguards the rights and interests of developing countries. The new understanding of CBDR will include historical responsibility, respective capacities and capabilities of countries, as well as national circumstances. The 2015 climate negotiations would be dedicated to "putting numbers on the table," which means each country's action would reflect its historical contributions to the cumulative levels of greenhouse gases, and also its wealth. ${ }^{18}$ From the interpretation of Madame Figueres,

the understanding of CDBR is developed from the accustomed historical responsibility to integrated cognition of historical responsibility, respective capabilities and different national circumstances. It is the really great revision to the convention principles.

16 “Gov[ernmen]t Must Reshape Strategy for New $\mathrm{CO}_{2}$ Framework," Daily Yomiuri, December 13, 2012.

${ }^{17}$ Saurabh Kumar, "Gloomy Climate at Doha," The Hindu Business Line, December 18, 2015, http://www.thehindubusinessline.com/opinion/gloomy-climate-atdoha/article4210155.ece.

${ }^{18}$ See the Climate Change Policy \& Practice project of the International Institute for Sustainable Development, "Lima Calls for Climate Action Lays Foundation for 2015 Agreement in Paris," December 15, 2014, http://climate-1.iisd.org/news/lima-call-for-climateaction-lays-foundation-for-2015-agreement-in-paris/. 


\section{Change of the Game: From Global Governance to Power Politics}

The structure of global climate change negotiations is thus moving back to great power politics. Different countries face different consequences of climate change, and distinct national interests have been formed. As a result, during the negotiations, many groupings that focused on climate could be observed, for instance, the EU, the Umbrella Group, Group of 77 plus China, Alliance of Small Island States (AOSIS) and Organization of Petroleum Exporting Countries (OPEC), amongst others. There are two themes running through the process of climate change negotiations. One is the inconsistency among members of the Umbrella Group, especially between the EU and the United States, the other is the disagreement between developing and developed countries. In addition, both of these themes became more obvious after the Doha conference. Although the traditional pattern of "two main groups" still exists, some kind of change has already happened in the situation created by tripartite powers (EU, U.S. and developing countries).

In order to persuade the U.S. into joining in "the 2015 agreement" and pulling the "firewall" down together, the EU temporarily abandoned its position for a "global treaty with legal framework" and gave its support to the U.S. The BASIC countries - Brazil, South Africa, India and China maintain their political unity and together with other LMDC members, have exerted their influence when countering the Western countries. Although claims from AOSIS, LDCs (least developed countries) and La Asociación Independiente de América Latina (AILAC) remain ambitious, these claims appear to be unachievable in the current context of great power politics. However, when examining the

Dynamics of global climate governance are heavily influenced by the ongoing geopolitical power shift. matter from other perspectives, the underestimation of and damage on AOSIS and LDC interests may also compromise the unity within the grouping of developing countries.

Under the new power competition of climate negotiations, the responsibilities of the newly emerging developing countries 
will continue to be seen as the focus of the negotiation. ${ }^{19}$ Developed countries have nevertheless tried to persuade these emerging developing countries to assume the climate obligations. In the 2015 climate negotiations, these emerging countries received much pressure from developed countries to follow the proposal to implement the qualified emissions after 2020. For these emerging countries that wish to continue rapid economic growth, this proposal is considered untenable. Meanwhile, it is also clear that developing countries' vulnerable positions remain largely unchanged vis-à-vis developed countries. In 1992, the Kyoto Protocol was created to bring the level of greenhouse gases to 7 percent below the 1990 level. Fiftyfive industrialized nations had to sign the protocol to lower their greenhouse emissions by 55 percent. This unprecedented treaty committed industrialized nations to making legally binding reductions. However, in recent years, as the international balance of power has shifted toward even distribution along with the accelerating political multi-polarization and globalization of the world economy, the international system is undergoing profound transformation. As a result, international climate negotiations are now at a crucial turning point. During the period of bi-adjustment and bitransformation on the structure of world politics, the global economy, as well as climate change negotiations, the climate negotiating process parallels the pattern of global politics and economy which can be described as "promotion on the East, demotion on the West." Since the 2008 financial crisis, the new emerging countries represented by Brazil, South Africa, Russia, India, and China (BRICS) have registered high economic growth; conversely, developed economies like the U.S., Japan, and the EU faced severe downturn pressure, with their positions in the global economic structure relatively degraded. Meanwhile, contribution of the BRICS countries to global economic growth has exceeded 50 percent. Share of Non-Annex I Parties in global economic output has increased from 17.9 percent in 1990 to 30.9 percent in 2012 (see Fig. 1). Global primary energy consumption grew by 1.8 percent in 2012, 90 percent of the overall contribution coming from China and India.

${ }^{19}$ Coral Davenport, "A Climate Accord Based on Global Peer Pressure," New York Times, December 15, 2014, http://www.nytimes.com/2014/12/15/world/americas/lima-climate-deal. html?_r=0. 


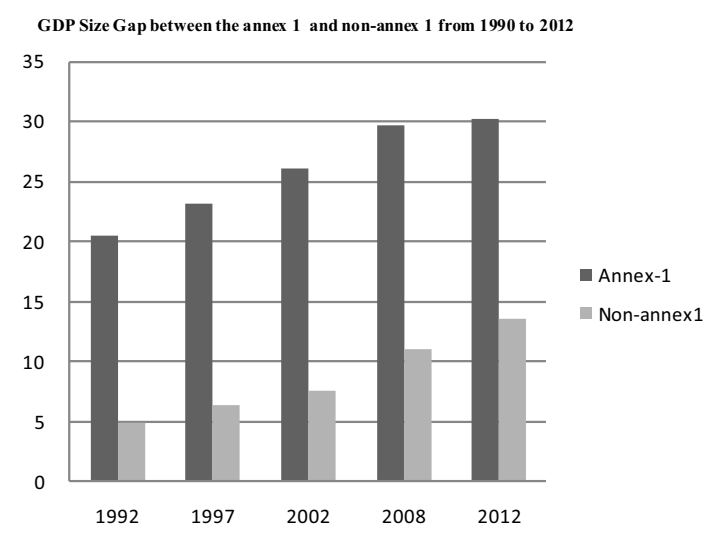

Fig. 1. GDP Size Gap between the Annex 1 and Non-Annex 1 from 1990 to 2012. Source: BP Statistic Review of World Energy 2015. ${ }^{20}$

The rising position of emerging countries in the world economy certainly represents a general trend. Meanwhile, developed countries' capacity to dominate the world economic order will be further restrained by developing countries, especially emerging countries. Twenty years after the Kyoto Protocol, factors such as capacity, potential, and economic power have changed tremendously among major negotiators; the core of the global emission structure has shifted onto chief developing countries. The U.S. and the EU have cast China and India into the spotlight, claiming that these countries should "show their cards," 21 and emphasized that countries like China and India which are enjoying high economic growth should participate in emission reduction. ${ }^{22}$ The EU on its own has also urged China and the U.S. to play more positive roles as great powers. During the negotiation process, responsibilities and positions of developing countries have changed constantly. Conflicts between developed and

${ }^{20} \mathrm{BP}$, Statistical Review of World Energy 2015, http://www.bp.com/content/dam/bp/pdf/ Energy-economics/statistical-review-2015/bp-statistical-review-of-world-energy-2015-fullreport.pdf.

${ }^{21}$ Frank McDonald, “Climate Deal Reached in Warsaw but Critics say it is too Weak in Face of Crisis," Irish Times.

22“Last-minute Deal at UN Climate Talks," FARS News Agency, November 24, 2013, http://www.highbeam.com/doc/1G1-350201769.html. 
developing countries have been transformed into those between highemission and low-emission countries. The concept of high-emission and low-emission countries was suggested by the U.S., and then supported by the EU and some other countries. This model is based on actual emissions and prospects of emission reduction. The global carbon dioxide emission in 2011 hit a new record of 34 billion tons, one-third of which were attributed to China and India, well-matched with the Organization for Economic Cooperation and Development (OECD) countries. For example, the amount of emissions per person in China is 7.2 tons, only 0.3 tons less than the EU level. ${ }^{23}$

\section{Future Trends of Global Climate Governance}

The driving forces behind the changes in the climate governance system described in the above section are the result of shifting domestic interests of each country. Developing countries, especially China, have had remarkable increase in carbon emissions due to rapid economic growth. In order to ensure energy security as well as to follow a low-carbon development path, these countries have to take actions. With similar concerns about energy and environmental security as well as economic growth, developed countries also have to expend more effort into their climate policies.

Evidently, the UN is a policy platform for global governance issues, but it is no longer the only driver of domestic decisions on carbon emission reduction. The UN says

it is already clear that promises for emission curbs at the UNFCCC will be too weak to get on track for a UN goal of limiting global warming to $2^{\circ} \mathrm{C}$ above pre-industrial times. ${ }^{24}$

Domestic interests of both developed and developing countries are much stronger factors that could drive more dramatic changes in global climate governance. The alliances of global climate change negotiation are becoming more fragmented than before. The management mechanism of

${ }^{23}$ Jos G., J. Olivier, Greet Janssens-Maenhout, and Jeroen A. H. W. Peters, Trend in Global $\mathrm{CO}_{2}$ Emissions (The Hague: PBL Netherlands Environmental Assessment Agency, 2012), p. 6.

24“Tough Task ahead on Climate Change Deal,” Pretoria News, December 16, 2014. 
climate change with the UNFCCC at the core has long been questioned. Cooperation mechanism patterns characterized by a concert of powers, e.g., the G20 and the major economic forums, as well as market resources patterns from bottom to top, grow continually between developed and developing powers. The U.S. has initiated processes about energy security and climate change issues for the main economies since 2007. The processes which aim at diminishing GHG emissions have included 17 most powerful economies in the world as its proponents, and the relations between the UN climate mechanisms and these processes can be describe as "ambiguous" or "conflicting." There are growing numbers of new alliances within the environmental field, and the majority of these alliances are formed between developed and developing countries; one of these is the Cartagena Dialogue for Progressive Actions under the EU. ${ }^{25}$ The growing discourse power of developing countries regarding various forms of international cooperation is the direct reflection of their soaring economic power. The rise of the BRICS, the Next-11 (Philippines, Bengal, Egypt, Indonesia, Iran, South Korea, Mexico, Nigeria, Pakistan, Turkey, Vietnam) and the VISTA (Vietnam, Indone-

\section{Global climate}

governance is gathering momentum not only from the increasing joint and individual efforts of various nations, but also from new technologies and improved ways of development. sia, South Africa, Argentina) all demonstrate the strengthening of the developing countries' position in world political and economic affairs.

It is obvious that these emerging economies, especially China, will face everincreasing pressure from developed countries during climate negotiations. With foundations such as CBDR fixed in the 1990s and the Kyoto Protocol, the "South and North Arrangement" on global climate governance was established, whereby developing countries accounted for only 32 percent of global carbon dioxide emissions. Developed countries are in the absolutely

${ }^{25}$ Duncan Clark, “Revealed: How Fossil Fuel Reserves Match UN Climate Negotiating Positions," The Guardian, February 13, 2012, http://www.theguardian.com/environment/ blog/2012/feb/16/fossil-fuel-reserves-un-climate-negotiating. 
dominant position in terms of emission reduction potential and actual emission. Thus there is a common view that developed countries ought to undertake reduction responsibility first, and deliver financial and technical assistance to developing countries. As previously mentioned, after more than 20 years of development, factors such as capacity, potential, and economic power have tremendously changed among negotiators. The potential of major developing countries in terms of emission reduction have been gradually increasing. From 2000 to 2030, two-thirds or threequarters of the growth of carbon emissions based on energy exploitation may be attributable to developing countries (see Figs. 1 and 2).

With the focus of climate governance being the reduction of carbon emissions, each country is currently facing four energy challenges in order to guarantee reliable and affordable energy supply and achieve rapid transformation of the energy supply systems to become low-carbon, efficient, and environmentally friendly. ${ }^{27}$ The global low-carbon future

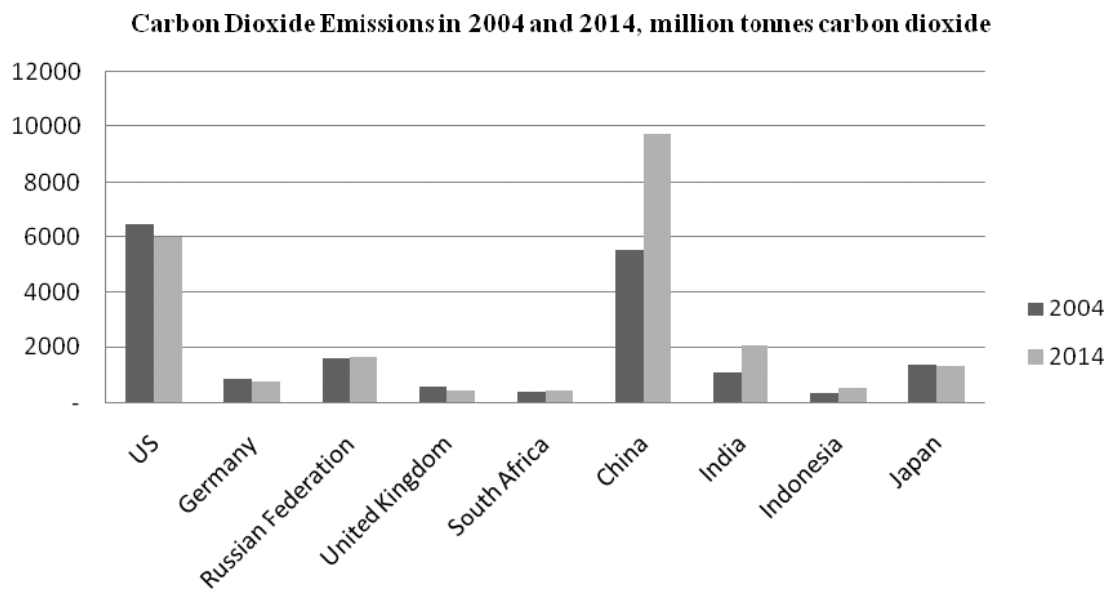

Fig. 2. Carbon Emissions in 2004 and 2014. ${ }^{26}$

Source: BP Statistical Review of World Energy 2015.

${ }^{26}$ BP, Statistical Review of World Energy 2014 pp.15-39, http://www.bp.com/content/dam/ bp/pdf/Energy-economics/statistical-review-2014/BP-statistical-review-of-world-energy2014-full-report.pdf.

${ }^{27}$ William D. Nordhaus, "Stern Review on the Economics of Climate Change," NBER Working Paper No. 12741 (Cambridge, Mass.: National Bureau of Economic Research, December 2006), http://www.hm-treasury.gov.uk/independent_reviews/stern_review_economics_climate_change/sternreview_index.cfm. 
and the emergence of low-carbon technology will enhance the energy industry worldwide and the strategic position of the equipment manufacturing industry. It is no exaggeration to say that the success of dealing with these four factors of energy security would determine the future prosperity of human society. Evidently, there is a correlation between energy competition driven by climate change and the international political economic environment, know-how, ability and possession of resources. The interaction of these factors constitutes the driving force for renewable energy development in the world (see Fig. 3).

Therefore, almost every country has adopted low-carbon fuels or clean energy as the new engine for economic growth. According to a UN report,

by 2012, 118 countries will have had climate change legislation or renewable energy targets more than double the number in 2005. There are increasing local, voluntary efforts to reduce deforestation and emissions not covered by the UN framework. In 2010, renewables accounted for 20.3 percent of worldwide electricity, compared with 3.4 percent in $2006 .^{28}$

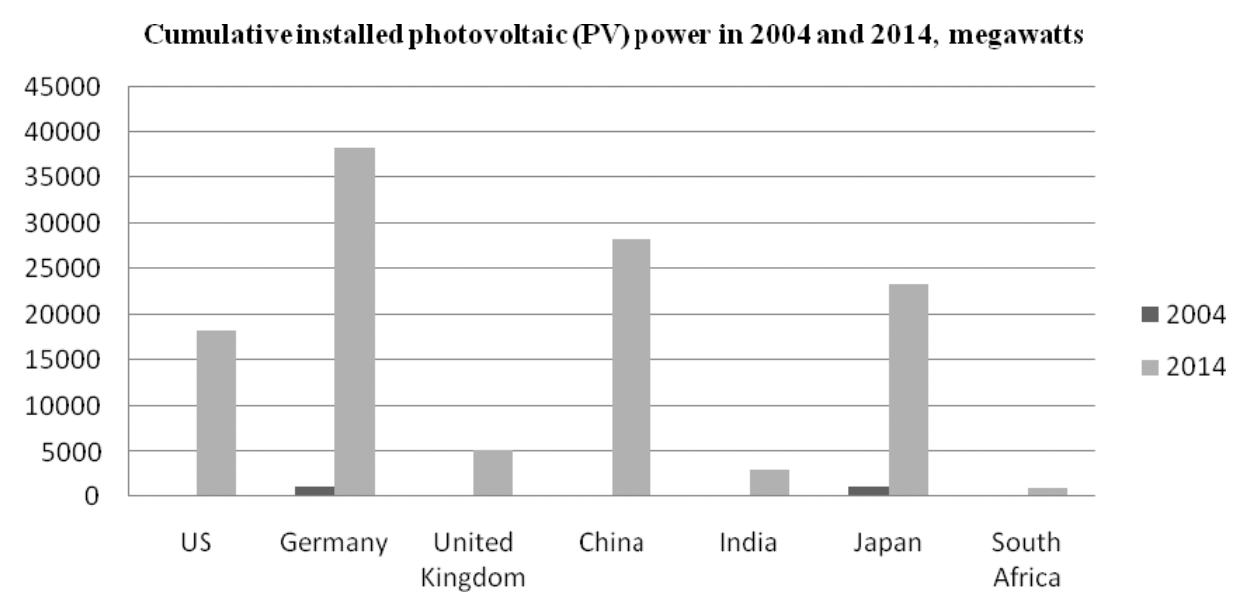

Fig. 3. Global Renewable (Solar) Energy Consumption.

Source: BP Statistical Review of World Energy 2015 (graph by the author).

${ }^{28}$ Christiana Figueres, "A Universal Climate Change Agreement Is Necessary and Possible," Inter Press Service, December 17, 2012, http://www.ipsnews.net/2012/12/op-ed-auniversal-climate-change-agreement-is-necessary-and-possible/. 
The solar photovoltaic, solar water heaters, and wind energy capacity of China is approaching the limit. The solar photovoltaic capacity is more than 10 million kilowatts and the wind energy capacity is more than 25 million per year. It is forecasted that China's solar power production will surpass that of Germany in 2015 and China's renewable energy consumption will take the lead in the world. In 2013, when addressing the Congress, U.S. President Barack Obama pointed out that

countries like China and Germany are going all [out] in the race for clean energy. I believe Americans build things better than anybody else. I want America to win that race, but we can't win it if we're not in it. So the plan I'm announcing today will help us double again our energy from wind and sun. Today, I'm directing the Interior Department to green light enough private, renewable energy capacity on public lands to power more than 6 million homes by $2020 .^{29}$

\section{China's Role to Play in Global Climate Governance}

The key challenge of global climate governance is how to coordinate the relations among China, the EU, and the U.S., and consistently protect the institutional construction of the Durban Platform under the UN framework. First of all, we have to admit that climate change has already effected dramatic changes in geoeconomics and geopolitics that the traditional model of top-down governance by the UN is hardly able to control the carbon emissions of each country under the endurable capacity of the earth. Moreover, it is true that competition has become the impetus for climate negotiations. The contests among great powers like China, the U.S. and the EU do not just exist in the "sum-up relations" in the Westphalian power system, as the competition regarding low-carbon technologies and renewable energy could facilitate the entirety and interdependence of the global development in new resources as well as increase the virtual discourse

${ }^{29}$ See the full transcript of Obama's Remarks on Climate Change on the The Wall Street Journal online, June 25, 2013, http://blogs.wsj.com/washwire/2013/06/25/full-transcript-ofobamas-remarks-on-climate-change/. 
power and advocacy rights of the emerging powers in new energy. Nowadays, China, the EU, the U.S., and other powers with advanced renewable energy production and installed capacities can play leading roles in climate governance, while other countries with renewable resources like Brazil and those in the Scandinavian region will have increasingly prominent positions. There are several things that China should do for its own sake and for global interests.

- China should promote a shift back to "great-power politics" or "greatpower governance," and improve the efficiency of the convention.

- China should be flexible in formulating the assessment and legal forms of the INDC, contributing to rebuilding credibility for the convention.

- China should adjust its negotiation strategy, maintain two kinds of interests - "development space" and "national image," and consider the strategy of "protecting the strategic sustentation of the developing countries" with discretion.

- China should develop its image as a "great power" and "host" in climate change governance.

- China should deeply understand the divisions among developing countries and strengthen cooperation with emerging countries.

As the biggest carbon emitter, China should commit itself to eco-friendly development and to playing a more active role in global climate governance.
In addition, the low-carbonizing of the socio-economic model is the trend of global development. Once a country has widely adopted advanced low-carbon technology, it will gain strategic advantage in international political and economic cooperation. The progress in low-carbon technology, especially the development of low-carbon technology in the energy and equipment manufacturing industries, will become a crucial precondition of improving economic competitiveness for all countries in the world.

China is now confronting the huge pressure of carbon emission reduction, and meanwhile facing new opportunities of development. China's socio-economic development strategy not only needs to take energy supply security into account, but also brings climate security and ecological 
security into the structure of national security and long-term development strategy, integrating energy and climate change into national strategic structure at the same time. The government needs to positively strengthen the construction of laws and regulations on climate change. The management institutions need to be set up and perfected, which can help create a good institutional policy and market environment for China's low-carbon development. Promoting China's low-carbon technology development, expanding the research on and spread of energy conservation, emission reduction and clean production technologies, bringing in the advanced energy technology positively and grasping the low-carbon core technology as early as possible are also required. It is an effective measure to promote energy conservation and emission reduction by developing the emission index deal and making use of market institution.

China's carbon trading institution is still imperfect and the market scale still needs to be expanded. Carbon trading needs to be integrated with the international market as soon as possible, in order to promote the necessary energy structure adjustment and clean energy development. The low-carbon concept will not only lead the revolution of economic development model, but also feature low-carbon consumption as a desired social norm, which can lead the transformation of national living and consumption models. Technology is the most important element in a long-term strategy to deal with climate change. At the technical level, Chinese science and technology have provided some effective tools to address climate change. China should vigorously develop energy-saving and energy efficient technologies, renewable energy and new energy technologies as well as clean coal. Other technologies to be explored and utilized include advanced nuclear energy, carbon capture and storage, bio-sequestration and carbon sequestration.

\section{Conclusion}

Climate change undermines the prosperity and security of all nations. The 2015 UN Paris Climate Conference aims to achieve interdependence and cooperation among developed and developing countries. However, the deficit of global climate governance is growing. The fight against global warming can be described in terms of common goods. Professor Robert Keohane once argued that, "If there is not an international regime, 
prospects for cooperation are bleak indeed, and dilemmas of collective action are likely to be severe." ${ }^{30}$ Unfortunately, neither developed nor developing countries agree on the common priority of protecting the earth's climate over safeguarding their different developmental interests and obligations. The 2015 climate negotiations call for questions about the seriousness, legitimacy and effectiveness of the convention. On the global scale, however, it has been scientifically proven that the "deficit" between the risk of global climate change and global climate governance is increasing due to the slow pace of the international climate negotiation progress. On one hand, historical responsibility has clearly given way to the idea of "national circumstances" justifying themselves at will, which poses challenges to seriousness and legitimacy; on the other hand, it has become more unrealistic to enhance emission reduction as well as provide longterm adequate funds. As most countries are satisfied with the status quo that "as long as I do not take more responsibility, I do not care about the others," true leaders are rare. Countries are choosing to play safe, and the climate cooperation under the framework of the convention will become increasingly looser and perfunctory. The deficit of climate change governance also reveals the weaknesses in negotiations and the policy-making approaches "driven by the signatories," making the text more cumbersome, which has to finally be given up or left as "a hopeless mess" for subsequent negotiations. Hence, "the outside established text" has to be the choice. With uncontrolled democracy, the convention will become an ineffective institution, further contributing to doubts on its effectiveness.

At present, developed countries not only hope that the 2015 UN Paris Climate Conference will conclude with a successful deal and push the Durban Action Enhancement Platform to reduce their historical responsibility, but they also expect that the Durban Platform could postpone the rise and development of China as well as maintain the international political and economic orders dominated by the West. UN Secretary-General Ban KiMoon hopes to "keep the international community on track for a comprehensive, legally binding agreement on the issue by $2015 .{ }^{\prime 31}$

${ }^{30}$ Robert O. Keohane, After Hegemony (Princeton, N.J.: Princeton University Press, 1984), p. 81.

31 “Ban Reviews UN's Challenges, Successes in 'Tumultuous' 2012," Xinhua News, December 20, 2012, http://news.xinhuanet.com/english/world/2012-12/20/c_124120252.htm. 
Looking into the future, the global climate governance system could benefit from the low-carbon economic growth discussed in the 2015 UN Paris Climate Conference. A concerted transition to a low- or zero-carbon economy is the reasonable direction for the developing world, especially with financial and technical aid from the developed world. Consequently, it is necessary for China and other countries to cooperate in the climate change sector, because the stability of the whole earth's ecological system is critical to each state. New energy revolutions caused by climate change form the foundation of becoming a global power. To be sure, China is wellpositioned to leap onto a clean energy development path. In the longer term, however, China could show genuine leadership on climate change in the developing world by transforming into an economy that generates fewer carbon emissions. Such choice would be greatly facilitated (and expedited) with financial and technical aid from developed countries. Nevertheless, even in the absence of such aid, it is clear that the Chinese government should integrate countermeasures against climate change into its development policy. Each country has to realize that only cooperation, rather than conflicts or zero-sum politics, is the right way to achieve climate security for the world. It is advisable and urgent for China to participate in the global energy and climate governance system, for the benefit of China itself and other countries in the world. 